\title{
ALKALOID FUROKUINOLIN DAN ASAM SINAMAT TER-O-GERANILASI DARI KULIT BATANG Melicope hookeri T.G. HARTLEY
}

\author{
Ratih Dewi Saputri, Tjitjik Srie Tjahjandarie, Mulyadi Tanjung*
}

Lab. Kimia Organik Bahan Alam, Departemen Kimia, Fakultas Sains dan Teknologi, Universitas Airlangga, Surabaya 60115, Indonesia

*Email korespondensi: mulyadi-t@ fst.unair.ac.id

\begin{abstract}
One furokuinoline alkaloid, evolitrine (1), and one cinnamate acid, trans 3-methyl-4-geranil caffeic acid (2) were isolated from the stem bark of Melicope hookeri. The structures of both compounds were determined based on spectroscopic data such as UV, IR, MS and NMR. Compounds 1-2 were evaluated for their anticancer activity against murin leukemia P-388 cells, showing their $\mathrm{IC}_{50}$ were 4,06 $\pm 0,15$ and $4,86 \pm 0,30 \mu \mathrm{g} / \mathrm{ml}$, and two compounds showed moderate activity.
\end{abstract}

Keywords: Melicope hookeri, furokuinoline alkaloid, cinnamate acid, anticancer

\begin{abstract}
ABSTRAK
Satu senyawa alkaloid furokuinolin yakni evolitrin (1) dan satu senyawa asam sinamat terO-geranilasi yakni asam trans 3-metil-4-geranil kafeat (2) telah diisolasi dari kulit batang Melicope hookeri. Struktur kedua senyawa ditetapkan berdasarkan analisis spektroskopi UV, IR, MS dan NMR. Uji aktivitas antikanker senyawa 1-2 terhadap murin leukemia P388 memperlihatkan $\mathrm{IC}_{50} 4,06 \pm 0,15$ dan $4,86 \pm 0,30 \mu \mathrm{g} / \mathrm{ml}$ dan kedua senyawa memperlihatkan aktivitas moderat.
\end{abstract}

Kata Kunci: Melicope hookeri, alkaloid furokuinolin, asam sinamat, antikanker

DOI: https://doi.org/10.25026/jsk.v2i1.93

\section{PENDAHULUAN}

Melicope hookerii merupakan salah satu tumbuhan endemik Kalimantan. Tumbuhan ini merupakan spesies dari famili Rutaceae dan dikenal dengan nama 'Ki Sampang'. Secara tradisional, tumbuhan ini dimanfaatkan masyarakat sebagai obat seperti diare, disentri, dan luka (Heyne, 1987). Tumbuhan Melicope terdiri dari 280 spesies dengan penyebaran di Asia, Afrika, Australia dan Polynesia. Melicope menghasilkan senyawa alkaloid, flavonoid, kumarin, asam sinamat dan memperlihatkan aktivitas antikanker, antifungal dan antioksidan (Kasim, 2013; Li, 2001; Ramli, 2004; Saputri, 2018; Simonsen, 2004; Tanjung, 2017).

Dalam rangka penelitian fitokimia senyawa alkaloid furokuinolin dan asam sinamat ter- $O$-geranilasi dari $M$. hookeri tumbuhan endemik Indonesia. Pada kesempatan kali ini akan dilaporkan penemuan satu senyawa alkaloid furokuinolin yakni evolitrin (1) dan satu senyawa asam sinamat ter- $O$-geranilasi yakni asam trans 3-metil-4-geranil kafeat (2) dari kulit batang $M$. hookerii. Selain itu juga akan dilaporkan aktivitas antikanker 
kedua senyawa terhadap sel murin leukemia P-388.

\section{METODE PENELITIAN}

\section{Prosedur Umum}

Spektrum UV ditetapkan dengan spektrofotometer UV-Vis Shimadzu 1800. Spektrum IR ditentukan dengan spektrofotometer IR Perkin Elmer. Spektrum massa ditentukan dengan spektrometer HR-ESI-MS merck Waters LCT XE ESI. Spektrum NMR ditentukan dengan spektrometer NMR JEOL ECA 400 yang beroperasi pada $400 \mathrm{MHz}\left({ }^{1} \mathrm{H}-\right.$ NMR) dan $100 \mathrm{MHz}$ ( ${ }^{13} \mathrm{C}$-NMR). Kromatografi kolom gravitasi menggunakan silika gel 60 (Merck), kromatografi radial menggunakan silika gel $60 \mathrm{PF}_{254}$ (Merck) dan kromatografi lapis tipis (KLT) menggunakan plat KLT silika gel $60 \mathrm{GF}_{254} 0.25 \mathrm{~mm}$ (Merck).

\section{Bahan tumbuhan}

Kulit batang $M$. hookeri diperoleh dari Desa Anjungan, Kecamatan Landak, Pontianak, Kalimantan Barat. Spesimen tumbuhan diidentifikasi di Herbarium Bogorienses, Lembaga Ilmu Pengetahuan Indonesia (LIPI) Biologi, Cibinong, Bogor, Jawa Barat.

\section{Ekstraksi dan isolasi alkaloid furokuinolin dan asam sinamat}

Ekstraksi kulit batang M. hookeri sebanyak $1,5 \mathrm{~kg}$ menggunakan metanol pada suhu kamar sebanyak dua kali selama 24 jam. Ekstrak metanol yang diperoleh dipekatkan dengan alat penguap bertekanan rendah sehingga diperoleh ekstrak kental metanol berwarna coklat $(200$ g). Ekstrak metanol selanjutnya dipartisi dengan $n$-heksana menghasilkan ekstrak $n$-heksana dan ekstrak metanol. Ekstrak metanol selanjutnya ditambahkan asam sulfat 5\% pH 3-4 kemudian dipartisi dengan etil asetat menghasilkan ekstrak etil asetat dan fasa asam. Ekstrak etil asetat (senyawa non alkaloid) dipekatkan dengan alat penguap bertekanan rendah menghasilkan ekstrak kental coklat sebanyak $20 \mathrm{~g}$. Fasa asam ditambahkan ammoniak $\mathrm{NH}_{4} \mathrm{OH}$ pekat sampai $\mathrm{pH}$ 8-9 untuk mengubah garam alkaloid menjadi alkaloid bebas (Tjahjandarie, 2015). Ekstraksi fasa basa dipartisi etil asetat menggunakan corong pisah menghasilkan ekstrak kasar alkaloid sebanyak $5 \mathrm{~g}$.

Pemisahan ekstrak etil asetat (19

g) dengan kolom kromatografi gravitasi menggunakan campuran eluen nheksana:etil asetat $(9: 1,8: 2$, dan 1:1) menghasilkan dua fraksi utama A-B. Berdasarkan analisis KLT, fraksi B memperlihatkan pendaran warna ungu dengan lampu UV. Pemisahan fraksi B (400 mg) dengan planar kromatografi radial dengan eluen $n$-heksana-aseton (9:1, 8:2 dan 7:3) menghasilkan senyawa 2 sebanyak $50 \mathrm{mg}$.

Pemisahan ekstrak alkaloid (4,5 g) dengan kolom kromatografi gravitasi menggunakan campuran eluen yang sama dengan pemisahan ekstrak etil asetat menghasilkan tiga fraksi utama A-C. Berdasarkan analisis KLT, fraksi C memperlihatkan spot berwarna coklat kemerahan dengan pereaksi Dragendorf. Hasil KLT ini menunjukkan bahwa fraksi $\mathrm{C}$ mengandung alkaloid. Pemisahan fraksi C (625 mg) dengan kolom kromatografi gravitasi menggunakan eluen nheksana:etil asetat (9:1, 8:2, 1:1 dan 3:7) menghasilkan tiga subfraksi yakni $\mathrm{C}_{1}-\mathrm{C}_{3}$. Pemisahan dan pemurnian subfraksi $\mathrm{C}_{2}$ $(125 \mathrm{mg})$ dengan planar kromatografi radial dengan eluen $n$-heksana-aseton (9:1, 8:2 dan 1:1) menghasilkan senyawa 1 sebanyak $15 \mathrm{mg}$.

\section{Uji aktivitas antikanker terhadap sel murin leukemia P-388}

Penentuan uji aktivitas antikanker senyawa 1-2 terhadap sel kanker murin leukemia P-388 menggunakan metode MTT assay (Tanjung, 2018; 2010; Tjahjandarie, 2017). Jumlah sel yang terinhibisi oleh masing-masing senyawa $\mathbf{1}$ dan 2 diukur serapannya dengan menggunakan microplate reader pada $\lambda$ 
$540 \mathrm{~nm}$ setelah diinkubasi selama 24 jam dalam incubator $\mathrm{CO}_{2}$ pada suhu $37^{\circ} \mathrm{C}$. Senyawa hasil isolasi dengan variasi konsentrasi $1000 ; 100 ; 30 ; 10 ; 3 ; 1 ; 0,3$ dan $0,1 \mu \mathrm{g} / \mathrm{ml}$ dengan perlakuan triplo diuji pada kultur sel murin leukemia P388. Nilai $\mathrm{IC}_{50}$ dapat dihitung melalui ektrapolasi garis $50 \%$ serapan senyawa uji terhadap berbagai konsentrasi menggunakan analisis regresi.

\section{HASIL DAN PEMBAHASAN}

Dua senyawa fenolik, senyawa evolitrin (1) dan asam trans 3-metil-4geranil kafeat (2) telah berhasil diisolasi dari kulit batang M. hookeri.

Evolitrin (1) berwujud padatan kuning muda memperlihatkan ion kuasimolekul positif $[\mathrm{M}+\mathrm{H}]^{+}$pada $\mathrm{m} / \mathrm{z}$ 230,0859 yang sesuai dengan rumus molekul $\mathrm{C}_{13} \mathrm{H}_{12} \mathrm{NO}_{3}$ berdasarkan hasil pengukuran HR-ESI-MS. Spektrum UV senyawa 1 dalam $\mathrm{MeOH}$ memperlihatkan serapan maksimum pada $\lambda_{\text {maks }}(\log \varepsilon): 224$ $(4,20), 290(3,34), 333(3,70), 345(3,69)$ dan $365(3,60) \mathrm{nm}$ yang merupakan ciri khas senyawa alkaloid furokuinolin (Tanjung, 2017). Spektrum IR senyawa 1 dalam $\mathrm{KBr}$ memperlihatkan pita serapan pada $v_{\text {maks: }} 1641 \mathrm{~cm}^{-1}$ (karbonil terkonyugasi), $1581,1411 \mathrm{~cm}^{-1} \quad(\mathrm{C}=\mathrm{C}$ aromatik) and $1188 \mathrm{~cm}^{-1}$ (C-O-C eter). Spektrum ${ }^{1} \mathrm{H}-\mathrm{NMR}$ (400 MHz, Tabel-1) senyawa 1 dalam $\mathrm{CDCl}_{3}$ memperlihatkan tiga sinyal proton aromatik dengan sistem $\mathrm{ABX}\left[\delta_{\mathrm{H}} 8,15(1 \mathrm{H}, d, J=9,2 \mathrm{~Hz}, \mathrm{H}-5)\right.$, $7,34(1 \mathrm{H}, d, J=2,4 \mathrm{~Hz}, \mathrm{H}-8)$ dan 7,09 $(1 \mathrm{H}, d d, J=9,2 ; 2,4 \mathrm{~Hz}, \mathrm{H}-6)]$ serta sepasang sinyal doublet cincin furo $(J=$ $2,9 \mathrm{~Hz})$ pada $\delta_{\mathrm{H}} 7,59(1 \mathrm{H}, s, \mathrm{H}-2)$ dan 7,05 $(1 \mathrm{H}, s, \mathrm{H}-3)$. Pola sinyal proton tersebut merupakan ciri khas senyawa alkaloid furokuinolin disubstitusi (Tanjung, 2017; Tjahjandarie, 2015). Spektrum ${ }^{1} \mathrm{H}-\mathrm{NMR}$ senyawa 1 memperlihatkan dua buah sinyal singlet metoksi pada $\delta_{\mathrm{H}} 4,45$ (7$\left.\mathrm{OCH}_{3}\right)$ dan 3,95 (4-OCH 3$)$. Spektrum ${ }^{13} \mathrm{C}-$ NMR (percobaan APT, $100 \mathrm{MHz}$, Tabel1) senyawa 1 dalam memperlihatkan 13 sinyal atom karbon yang terpisah secara sempurna dan posisi karbon telah dikonfirmasikan dengan spektrum HMQC dan HMBC. Berdasarkan analisis spektrum HMBC (Tabel-1), sinyal proton cincin furo pada $\delta_{\mathrm{H}} \quad 7,05 \quad(\mathrm{H}-3)$ menunjukkan korelasi dengan dua sinyal karbon oksiaril pada $\delta_{\mathrm{C}} 164,5$ (C-9a), $\delta_{\mathrm{C}}$ 161,2 (C-4) dan satu sinyal karbon kuarterner pada $\delta_{\mathrm{C}} 113,5$ (C-3a). Sinyal singlet metoksi $\delta_{\mathrm{H}} \quad 3,95 \quad\left(4-\mathrm{OCH}_{3}\right)$ memperlihatkan korelasi dengan sinyal karbon oksiaril pada $\delta_{\mathrm{C}} 161,2$ yang mempertegas kedudukan oksiaril terikat di C-4. Sinyal proton aromatik pada 8,15 (H5) memperlihatkan korelasi dengan dua sinyal karbon oksiaril pada $\delta_{\mathrm{C}} 157,2(\mathrm{C}-7)$, $\delta_{\mathrm{C}} 161,2$ (C-4) dan satu sinyal karbon kuarterner pada $\delta_{\mathrm{C}} 147,7$ (C-8a). Sinyal singlet metoksi $\delta_{\mathrm{H}} \quad 4,45 \quad\left(7-\mathrm{OCH}_{3}\right)$ memperlihatkan korelasi dengan sinyal karbon oksiaril pada $\delta_{\mathrm{C}} 157,2$ dan mempertegas kedudukan oksiaril tersebut terikat di C-7. Sinyal proton aromatik pada 7,34 (H-8) berkorelasi dengan satu sinyal karbon kuarterner pada $\delta_{\mathrm{C}} 102,0(\mathrm{C}-4 \mathrm{a})$ dan satu sinyal karbon metin pada $\delta_{\mathrm{C}} 116,8$ (C-6). Demikian juga sinyal proton aromatik pada 7,09 (H-6) menunjukkan korelasi dengan dua sinyal karbon kuarterner pada $\delta_{\mathrm{C}} 102,0(\mathrm{C}-4 \mathrm{a})$ dan $\delta_{\mathrm{C}}$ 147,7 (C-8a). Berdasarkan analisis spektrum HMBC tersebut maka disimpulkan bahwa senyawa $\mathbf{1}$ adalah senyawa evolitrin (Chen, 2002). Korelasi antara sinyal proton dengan sinyal karbon dalam dua atau tiga ikatan pada spektrum HMBC yang utama untuk mendukung struktur senyawa evolitrin hasil isolasi dapat dilihat pada Tabel-1 dan Gambar-2. 
<smiles>COc1ccc2c(OC)c3ccoc3nc2c1</smiles>

(1)<smiles>COc1cc(/C=C/C(=O)O)ccc1OC/C=C(\C)C[C]C=C(C)C</smiles>

(2)

Gambar 1. Struktur evolitrin (1) dan asam trans 3-metil-4-geranil kafeat (2)

Tabel-1. Data spektrum ${ }^{1} \mathrm{H}$ dan ${ }^{13} \mathrm{C}-\mathrm{NMR}$ senyawa evolitrin dalam $\mathrm{CDCl}_{3}$.

\begin{tabular}{llrl}
\hline No.C & \multicolumn{1}{l}{$\delta_{\mathrm{H}}($ mult, $J$ dalam Hz $)$} & $\delta_{\mathrm{C}}$ & HMBC \\
\hline 2 & $7,57(d, 2,9)$ & 142,6 & $\mathrm{C}-3 ; \mathrm{C}-9 \mathrm{a}$ \\
3 & $7,05(d, 2,9)$ & 105,0 & $\mathrm{C}-3 \mathrm{a} ; \mathrm{C}-4 ; \mathrm{C}-9 \mathrm{a}$ \\
$3 \mathrm{a}$ & - & 113,5 & - \\
4 & - & 161,2 & - \\
$4 \mathrm{a}$ & - & 102,0 & - \\
5 & $8,15(d, 9,2)$ & 123,7 & $\mathrm{C}-4 ; \mathrm{C}-7 ; \mathrm{C}-8 \mathrm{a}$ \\
6 & $7,09(d d, 9,2 ; 2,4)$ & 116,8 & $\mathrm{C}-4 \mathrm{a}, \mathrm{C}-8 \mathrm{a}$ \\
7 & - & 157,2 & - \\
8 & $7,34(d, 2,4)$ & 106.0 & $\mathrm{C}-4 \mathrm{a} ; \mathrm{C}-6$ \\
$8 \mathrm{a}$ & - & 147,7 & - \\
$9 \mathrm{a}$ & - & 164,5 & - \\
$4-\mathrm{OCH}_{3}$ & $3,95(s)$ & 55,5 & $\mathrm{C}-4$ \\
$7-\mathrm{OCH}_{3}$ & $4,45(s)$ & 59,1 & $\mathrm{C}-7$ \\
\hline
\end{tabular}

Asam trans 3-metil-4-geranil kafeat (2) berwujud padatan kuning memperlihatkan ion kuasimolekul positif $[\mathrm{M}+\mathrm{H}]^{+}$pada $\mathrm{m} / \mathrm{z}, 331,1186$ yang sesuai dengan rumus molekul $\mathrm{C}_{20} \mathrm{H}_{27} \mathrm{O}_{4}$. Spektrum UV senyawa 2 dalam $\mathrm{MeOH}$ memperlihatkan serapan maksimum pada $\lambda_{\text {maks }}(\log \varepsilon): 260(3,68)$ dan $310(3,90) \mathrm{nm}$ yang merupakan ciri khas senyawa sinamat (Ramli, 2004). Spektrum IR senyawa 1 dalam $\mathrm{KBr}$ memperlihatkan pita serapan pada $v_{\text {maks }}: 3302 \mathrm{~cm}^{-1}$ (hidroksi), $1660 \quad \mathrm{~cm}^{-1} \quad$ (karbonil terkonyugasi), 1560, $1409 \mathrm{~cm}^{-1} \quad(\mathrm{C}=\mathrm{C}$ aromatik) and $1135 \mathrm{~cm}^{-1}$ (C-O-C eter) (Tanjung, 2010). Spektrum ${ }^{1} \mathrm{H}-\mathrm{NMR}$ (Tabel-2) senyawa 2 dalam $\mathrm{CDCl}_{3}$ memperlihatkan tiga sinyal proton aromatik dengan sistem $\mathrm{ABX}$ pada $\delta_{\mathrm{H}} 7,11$ $(1 \mathrm{H}, d d, J=8,4 ; 1,6 \mathrm{~Hz}, \mathrm{H}-6), 7,07(1 \mathrm{H}, d$, $J=1,6 \mathrm{~Hz}, \mathrm{H}-2)$ dan $6,87(1 \mathrm{H}, d, J=8,4$
$\mathrm{Hz}, \mathrm{H}-5)$ serta sepasang sinyal doublet trans vinilik $(J=15,8 \mathrm{~Hz})$ pada $\delta_{\mathrm{H}} 7,73$ $(1 \mathrm{H}, s, \mathrm{H}-2$ ') dan $6,32(1 \mathrm{H}, s, \mathrm{H}-1$ ') yang merupakan ciri khas sinyal proton asam sinamat disubstitusi (Ramli, 2004). Senyawa 2 memperlihatkan satu sinyal singlet metoksi pada $\delta_{\mathrm{H}} 3,91(3 \mathrm{H}, s, 3-$ $\mathrm{OCH}_{3}$ ). Analisis spektrum ${ }^{1} \mathrm{H}-\mathrm{NMR}$ juga memperlihatkan sinyal proton oksigeranil $\left[\delta_{\mathrm{H}} 5,50(\mathrm{H}-2\right.$ ''), 5,07 (H-6') $), 4,66(\mathrm{H}-$ 1''), 2,11 (H-5'), 2,08 (H-4'), 1,74 (H10'), 1,66 (H-8') dan 1,59 (H-9'”)]. Spektrum ${ }^{13} \mathrm{C}-\mathrm{NMR}$ senyawa 2 dalam memperlihatkan 20 sinyal atom karbon yang terpisah secara sempurna. Dua sinyal karbon oksiaril pada $\delta_{\mathrm{C}} 150,9(\mathrm{C}-4)$ dan $\delta_{\mathrm{C}}$ 149,6 (C-3) serta satu sinyal karbon karbonil dari asam karboksilat terlihat pada $\delta_{\mathrm{C}} \quad 172,9$ (C-3') menunjukkan senyawa 2 merupakan senyawa turunan asam kafeat. Penempatan kedudukan 
metoksi dan oksiaril pada struktur asam sinamat ditetapkan berdasarkan analisis spektrum HMQC dan HMBC. Analisis spektrum HMBC, sinyal proton trans vinilik pada $\delta_{\mathrm{H}} \quad 6,32 \quad\left(\mathrm{H}-1^{\prime}\right)$ memperlihatkan korelasi dengan sinyal karbon asam karboksilat pada $\delta_{\mathrm{C}} 172,9$ (C3') dan satu sinyal karbon kuarterner cincin benzena pada $\delta_{\mathrm{C}} 126 ., 9(\mathrm{C}-1)$. Sinyal proton aromatik pada $\delta_{\mathrm{H}} 7,07(\mathrm{H}-2)$ berkorelasi dengan dua sinyal karbon oksiaril pada $\delta_{\mathrm{C}} 149,6(\mathrm{C}-3)$ dan $\delta_{\mathrm{C}} 150,9$ (C-4); satu sinyal karbon kuarterner pada $\delta_{\mathrm{C}} 126 ., 9(\mathrm{C}-1)$ serta satu sinyal karbon metin aromatik pada $\delta_{\mathrm{C}} 123,1$ (C-6). Sinyal proton aromatik pada $\delta_{\mathrm{H}} 7,11(\mathrm{H}-6)$ berkorelasi dengan sinyal karbon oksiaril pada $\delta_{C} 150,9(C-4)$ dan satu sinyal karbon metin pada $\delta_{\mathrm{C}} 109,9(\mathrm{C}-2)$. Sinyal proton oksimetilen pada $\delta_{\mathrm{H}} 4,66 \quad\left(\mathrm{H}-1{ }^{\prime}{ }^{\prime}\right)$ memperlihatkan korelasi dengan satu sinyal karbon oksiaril pada $\delta_{\mathrm{C}} 150,9(\mathrm{C}-4)$, satu sinyal karbon kuarterner pada $\delta_{\mathrm{C}}$ 141,3 (C-3''), dan satu sinyal karbon metin pada $\delta_{\mathrm{C}} 119,2$ (C-2'"). Hasil korelasi proton oksimetilen dengan ketiga sinyal karbon menunjukkan substituen oksigeranil terikat di C-4. Sinyal proton metoksi pada $\delta_{\mathrm{H}} \quad 3,91 \quad\left(3-\mathrm{OCH}_{3}\right)$ berkorelasi dengan sinyal karbon oksiaril pada $\delta_{\mathrm{C}} 149,6$ yang menunjukkan metoksi terikat di-C-3. Berdasarkan analisis spektrum HMBC maka senyawa 2 adalah asam trans 3-metil-4-geranil kafeat (Ramli, 2004)). Korelasi antara sinyal proton dengan sinyal karbon pada spektrum HMBC yang mendukung struktur senyawa 2 dapat dilihat pada Tabel-2 dan Gambar-2.

Tabel-2. Data spektrum ${ }^{1} \mathrm{H}$ dan ${ }^{13} \mathrm{C}-\mathrm{NMR}$ asam trans 3-metil-4-geranil kafeat dalam $\mathrm{CDCl}_{3}$.

\begin{tabular}{|c|c|c|c|}
\hline No.C & $\delta_{\mathrm{H}}($ mult, $J \mathrm{~Hz})$ & $\delta_{\mathrm{C}}$ & HMBC \\
\hline 1 & - & $126 ., 9$ & - \\
\hline 2 & $7,07(d, 1,6)$ & 109,9 & C-1; C-3; C-4; C-6 \\
\hline 3 & - & 149,6 & - \\
\hline 4 & - & 150,9 & - \\
\hline 5 & $6,87(d, 8,4)$ & 112,5 & $\mathrm{C}-1 ; \mathrm{C}-4$ \\
\hline 6 & $7,11(d d, 8,4 ; 1,6)$ & 123,1 & $\mathrm{C}-2 ; \mathrm{C}-4$ \\
\hline 1 ' & $6,32(d, 15,8)$ & 114,8 & $\mathrm{C}-1 ; \mathrm{C}-3$ ' \\
\hline 2' & $7,73(d, 15,8)$ & 147,2 & C-1; C-2; C-6, C-1'"'; C-3', \\
\hline 3 ' & - & 172,9 & - \\
\hline 1 ', & $4,66(d, 6,4)$ & 65,9 & C-4; C-2'”; C-3', \\
\hline 2 " & $5,50(d, 6,5)$ & 119,2 & $\mathrm{C}-4{ }^{\prime \prime} ; \mathrm{C}-10 '$ \\
\hline $3 "$ & - & 141,3 & - \\
\hline $4{ }^{\prime \prime}$ & $2,08(m)$ & 39,6 & C-2'” C-3', C-5'”, C-10' \\
\hline 5, & $2,11(m)$ & 26,3 & C-3'”; C-4’'; C-6”'; C-7'” \\
\hline $6 "$ & $5,07(d, 5,5)$ & 123,8 & C-4'”; C-8'’; C-9'” \\
\hline 7 ' & - & 131,9 & - \\
\hline 8, & $1,66(s)$ & 25,8 & C-6'"; C-7'”; C-9'” \\
\hline $9{ }^{\prime}$ & $1,59(s)$ & 17,8 & C-6'"; C-7'”; C-8' \\
\hline $10 ’$ & $1,74(s)$ & 16,8 & C-2'"; C-3'"; C-4' \\
\hline $3-\mathrm{OCH}_{3}$ & $3,91(s)$ & 56,0 & $\mathrm{C}-3$ \\
\hline
\end{tabular}




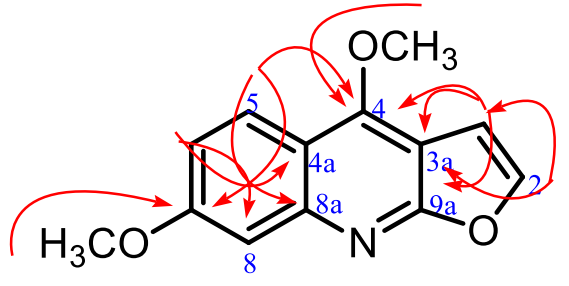

(1)

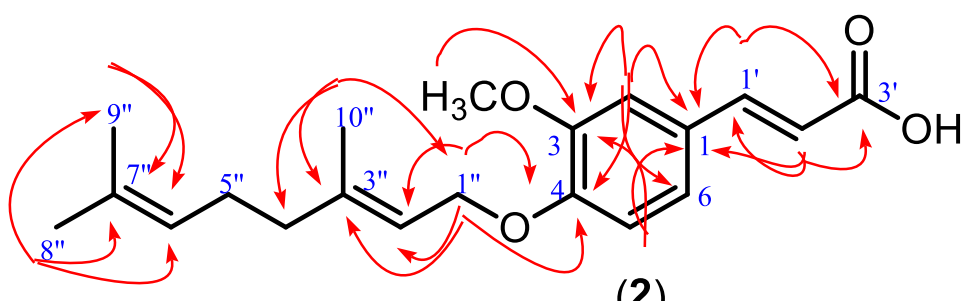

(2)

Gambar 2. Korelasi HMBC yang utama pada senyawa 1-2

Uji aktivitas antikanker senyawa $\mathbf{1}$ dan 2 terhadap sel murin leukemia P-388 memperlihatkan nilai konsentrasi daya hambat $\mathrm{IC}_{50}$ adalah 4,06 $\pm 0,15$ dan 4,86 \pm $0,30 \mu \mathrm{g} / \mathrm{ml}$. Kedua senyawa dikategorikan memiliki keaktifan moderat.

\section{KESIMPULAN}

Satu senyawa alkaloid furokuinolin yakni evolitrin (1) dan satu senyawa asam sinamat yakni asam trans 3-metil-4-geranil kafeat (2) telah berhasil dipisahkan dari kulit batang $M$. hookeri. Kedua senyawa memperlihatkan aktivitas moderat dengan nilai $\mathrm{IC}_{50}$ sebesar 4,06 \pm 0,15 dan 4,86 $\pm 0,30 \mu \mathrm{g} / \mathrm{ml}$.

\section{UCAPAN TERIMAKASIH}

Ucapan terimakasih disampaikan kepada Ismail Rachman, staff Botani, LIPI Biologi, Cibinong, Bogor atas voucher dan identifikasi tumbuhan.

\section{DAFTAR PUSTAKA}

Chen, J-J.; Chang, Y-L.; Teng, C-M.; Su, C-C.; Chen I-S., 2002. Quinoline alkaloids and anti-platelet aggregation constituents from the leaves of Melicope semecarpifolia. Planta Med., 68, 790-793.

Heyne, K., 1987. Tumbuhan Berguna Indonesia, Jilid II, Badan Penelitian dan Pengembangan Kehutanan, Departemen Kesehatan Republik Indonesia, Jakarta.
Kassim, N.K., Rahmani, M., Ismail, A., Sukari, M.A., Ee, G.C.L., Nasir, N.M., Awang, K., 2013. Antioxsidant activity-guided separation of coumarins and lignan from Melicope glabra (Rutaceae). Food Chem. 139: 8792.

Li, S-G., Tian, H-Y., Ye, W-C., Jiang, RW. 2011. Benzopyrans and furoquinoline alkaloids from Melicope ptelefolia. Biochem. Sys. Ecol.39: 64-67.

Ramli, I., Kamarulzaman, N.H., Shaari, K., Ee, G.C.L., 2004, p-OGeranylcoumaric acid from Melicope lunu-ankeda, Nat. Prod. Res., 18(4): 289-294.

Simonsen, H.T., Adsersen, A,. Bremner, P,. Heinrich, M., Smitt, U.W., Jaroszewski, J.W. 2004. Antifungal constituents of Melicope borbonica. Phytoter. Res. 18: 542-545.

Saputri, R.D., Tjahjandarie, T.S., Tanjung, M. 2018. Alkaloid kuinolin dari Melicope denhamii dan uji aktivitas antikankernya. Jurnal Sains dan Kesehatan. 9(1): 505-509.

Tanjung, M., Saputri, R.D., Tjahjandarie, T.S., $2017 . \quad 4-$ Methoxy-3-(3-methylbut-2-en1-yl)-7-((3-methylbut-2-en-1yl)oxy) quinolin-2(1H)-one from Melicope moluccana T.G. Hartley. Molbank. M939. 2: 1-5. 
Tanjung, M., Rachmadiarti, F., Saputri, R.D., Tjahjandarie, T.S. 2018. Mesucalophylloidin, a new isoprenylated 4-phenylcoumarin from Mesua calophylloides (Ridl.) Kosterm. Nat. Prod. Res. 32(9): 1062-1067.

Tanjung M, Mujahidin D, Hakim EH, Darmawan A, Syah Y.M. 2010. Geranylated flavonols from Macaranga rhizinoides. Nat Prod Commun. 5:1209-1211.
Tjahjandarie, T.S., Tanjung, M., 2015. Lead compound antimalaria dan antioksidan senyawa alkaloid, flavonoid, dan kumarin dari Limonia accidisima L. Laporan Akhir Penelitian Unggulan Perguruan Tinggi, Universitas Airlangga. 1-45.

Tjahjandarie, T.S.; Saputri, R.D.; Tanjung, M. 2017. 5,9,11Trihydroxy-2,2-dimethyl-3-(2methylbut-3-en-2-yl)pyrano[2,3a] xanthen-12(2H)-one from the stem bark of Calophyllum tetrapterum Miq. Molbank. M936. 1: 1-5. 